\title{
Clinical Risk Factors for Preterm Birth
}

\author{
Ifeoma Offiah, Keelin O'Donoghue and Louise Kenny \\ Anu Research Centre, Cork University Maternity Hospital \\ Ireland
}

\section{Introduction}

\subsection{Definitions}

Preterm birth (PTB) refers to the birth of a baby that occurs before 37 completed weeks of gestation. PTB can be further sub-categorized as late preterm delivery- 34 to 36 completed weeks gestation, moderately preterm- 32 to 34 completed weeks, very preterm- less than 32 weeks, and extremely preterm- less than 28 weeks gestation (Lockwood, et al., 2011). Preterm birth can also be defined by birth weight: low birth weight- less than $2500 \mathrm{~g}$, very low birth weight- 1500g, and extremely low birth weight- less than 1000g (Lockwood, et al., 2011).

\subsection{Significance}

Preterm birth is an increasingly common complex condition with multiple risk factors (Allen, 2008) and has substantial medical, psychological, economic and social impacts. It is the leading cause of infant mortality in the United States. Compared with term neonates, mortality rates for preterm (less than 37 weeks) and very preterm infants (less than 32 weeks) are 15-fold and 75-fold higher respectively (Mathews, et al., 2004). The organs most commonly affected by preterm delivery are the lungs, as the lungs are one of the last organs to develop in utero. Preterm birth is also the most important determinant of short and long term morbidity in infants and children, and can have serious long term health consequences, such as cerebral palsy, blindness, developmental difficulties, including cognitive, sensory, learning and language deficits (Allen, 2008). The younger the gestation, the greater the risk of severe morbidity. The EPIPAGE study group reported a twofold increased prevalence of hyperactivity, inattention and peer problems in very preterm birth children at school ages when compared to children born at term (Delobel-Ayoub, et al., 2009). Additionally, preterm birth and low birth weight is associated with cardiovascular disease in adult life (Barker, et al., 1993).

\subsection{Incidence}

Significant progress has been made in the care of premature infants, but not in reducing the prevalence of preterm birth (Goldenberg, et al., 2008). In the United States, there has been a $21 \%$ rise in the rate of preterm births since 1990, which peaked in 2006 with $12.8 \%$ of all 4 million annual live births born at less than 37 weeks of gestation (Russell, et al., 2007). The incidence in Europe and other developed countries lies between 5-9\% (Goldenberg, et al., 2008). East Asian and Hispanic women typically have a low pre-term birth rate. However, the incidence of preterm birth continues to rise. Part of this escalation is due to the increased 
indicated preterm delivery of artificially conceived multiple pregnancies, which account for $15-20 \%$ of all pre-term births (Goldenburg, et al., 2008).

Preterm birth is the principal cause of infant mortality in developed countries. One in 8 births in the United States in 2005 were preterm, compared to 1 in 18 births in Ireland and Finland. The infant mortality rate in Ireland in 2010 was 3.89 per 1000 live births and in the United States 6.8 per 1000 live births. The main cause of the United States' high infant mortality rate when compared with Europe is the very high percentage of preterm births in the United States, the period when infant mortality is greatest (Mac Dorman \& Mathews, 2010).

\subsection{Economic implications}

The cost associated with providing care for preterm infants, who may spend numerous months in hospital, has significant implications for the economy. In the UK, $75 \%$ of neonatal deaths, and the majority of neonatal intensive care admissions, are due to preterm infants.

A nationwide survey carried out by Russell and colleagues in 2001, regarding the hospital cost of preterm infants showed that in the United States, in 2001, 4.6 million infants were hospitalized, costing $\$ 12.4$ billion. Of these, $8 \%$ of hospitalizations were for preterm or low birth weight infants, the hospital care cost of which totaled $\$ 5.8$ billion. This represents $47 \%$ of the costs for all infant hopitalizations. This cost is partly explained by the increased cost of caring for a preterm infants in hospital, $\$ 15,100$, and an extremely preterm infant, $\$ 65,600$, versus $\$ 600$ for an uncomplicated newborn. Additionally, preterm infants and extremely preterm infant have, on average, an increased length of stay in hospital than uncomplicated newborns: 12.9 days and 42.2 days versus 1.9 days respectively (Russell, et al., 2007). This data suggests that major infant and paediatric cost savings can be achieved by the identification and prevention of preterm birth.

\section{Risk factors}

Several factors have been identified that are associated with preterm birth. These include intrauterine inflammation/ infection, uterine overdistension, uteroplacental ischaemia / haemorrhage, and stress. However, an association does not establish causality.

Mothers exposed to high levels of psychological or social stresses are at increased risk of pre-term birth. Additionally, exposure to severe life events, has also been linked to very and extremely pre-term births. Clinical depression, possibly due to its associated increase in smoking, alcohol and drug use also plays a role in increasing pre-term birth as mediated by these behaviours. Tobacco use alone increases the pre-term birth rate by almost 2 fold, due to the associated increased risk of small for gestational age and placental abruption. There are also marked ethnic differences in the incidence and aetiology of preterm birth, with African American women being consistently at increased risk of preterm birth compared to native white women.

As the cause of labour still remains elusive, the exact cause of preterm birth is also uncertain.

Approximately $30-35 \%$ of preterm births are indicated or iatrogenic due to medical or obstetric complications, $40-45 \%$ are related to spontaneous preterm labour, and $25-30 \%$ to preterm prelabour rupture of membranes (PPROM). Spontaneous pre-term birth is most 
commonly caused by pre-term labour in Caucasians, and PPROM in black women indicating the existence of potentially different causative mechanisms. This chapter will review the current literature on established and putative risk factors for spontaneous preterm labour and PPROM.

\subsection{Previous preterm birth}

The risk of preterm birth is increased among women who have had a previous preterm birth (Iams et al., 1998). Previous preterm birth is the strongest risk factor for repeated preterm delivery and recurrences often occur at a similar gestational age, with around $70 \%$ delivering within 2 weeks of the gestational age of their first preterm delivery (Bloom, et al., 2001). Yet, the majority of mothers who have had a preterm delivery will go on to have a subsequent term delivery. Term births decrease the risk of PTB in subsequent pregnancies. Some risk factors of preterm delivery, if not adequately treated or permanent, persist in subsequent pregnancies.

Given the strong risk of recurrence, the genetic aspects of preterm delivery have become a matter of keen interest. Several studies suggest that a new partner between pregnancies reduces the risk of preterm delivery. A study carried out by Li suggested that among women with a preterm delivery at gestational age less than 34 weeks, changing partners resulted in a $33 \%$ reduction in the risk of preterm delivery in the subsequent pregnancy, compared to those who did not change partners (Li, 1999). However, a change in partners may reflect an association with long inter-pregnancy intervals rather than the influence of the partner's genetics per se. A more recent and extensive study of this hypothesis suggested that fathers contributed little to the preterm delivery risk (Wilcox, et al., 2008).

Genetic researchers have instead concentrated on both maternal and fetal genes, as poor perinatal outcomes can, in principle, be affected by both the maternal genotype and the fetal genotype (Wilcox, et al., 2008). It is obvious that fetal genes can affect fetal wellbeing. However, the role of maternal genetics in fetal health and pregnancy outcome is more subtle.

Wilcox et al, 2008, carried out a study to investigate familial recurrence of preterm birth, and analyze the relative contributions of maternal and fetal genotypes to the risk of preterm delivery. They concluded that the recurrence risk of preterm birth was transmitted through the mother, with a higher risk if the mother was born preterm herself. There was no increased risk with the father's previous history or genetic input (Wilcox, et al., 2008). Other studies implicate a significant increase in risk to children, whose older siblings were affected by preterm birth, due to maternal and / or fetal genetic influences (Plunkett, et al., 2008). This increased risk still persists even after adjustment for common non-genetic environmental risk factors in families.

\section{2 latrogenic preterm delivery}

Iatrogenic preterm delivery accounts for more than $30 \%$ of all preterm deliveries. The preterm birth rate continues to escalate in many countries worldwide because of an increase in the indicated preterm births rate (Goldenberget al., 2008). Pre-eclampsia and placental abruption affects approximately $7 \%$ and $1 \%$ of all pregnancies, respectively. Along with intrauterine growth restriction and premature rupture of the membranes, they represent the most common reasons for indicated preterm delivery (Goldenberg, 2008, Plunket, 2008). Multiple gestations make up $10 \%$ of all preterm births, the majority of which, $(50 \%)$, are 
delivered preterm due to medical indications (Moutquin, 2003). The Obstetrician has to weigh up the benefits of allowing the pregnancy to continue in order to achieve improved perinatal outcome for the preterm infant, against delivering the fetus early for the health of the mother and infant. In 1995, The American College of Obstetricians and Gynecologists reported a survival rate for newborns at 34 weeks gestation as being within $1 \%$ of those born at or beyond 37 weeks (Hauth, 2006).

\subsection{Preterm prelabour rupture of membranes}

Preterm Prelabour Rupture of Membranes (PPROM) complicates only 2\% of pregnancies but is associated with $40-45 \%$ of preterm deliveries. It can occur spontaneously or can be iatrogenic following invasive procedures such as diagnostic amniocentesis or cervical surgery. PPROM together with spontaneous preterm labour accounts for almost $75 \%$ of all cases of preterm birth. At less than 37 weeks' gestation rupture of the membranes places the mother and the fetus at increased risk of short-term and long-term morbidity and mortality. The three causes of neonatal death associated with PPROM are prematurity, sepsis and pulmonary hypoplasia. Women with intrauterine infection deliver earlier than non-infected women and infants born with sepsis have a mortality rate four times higher than those without sepsis (RCOG, Green-top Guideline No. 44, 2010).

The decision to deliver the fetus prematurely or to manage the pregnancy expectantly following a diagnosis of PPROM requires careful assessment of the dangers related to prematurity in pregnancies delivered earlier compared with the development of intrauterine infection in those pregnancies managed expectantly. Since the 1970s expectant management has been the standard treatment for PPROM (Alexander \& Cox, 1996). Controversy exists over the gestational age at which expectant management should be abandoned and active interventions to effect delivery pursued. The Royal College of Obstetricians and Gynaecologists, Green-top Guideline, No. 44, recommend delivery at 34 weeks' gestation due to the increased risk of chorioamnionitis thereafter (RCOG, Green-top Guideline No. 44, 2010).

\subsection{Antepartum haemorhage}

Vaginal bleeding in early pregnancy has been consistently shown to be an independent risk factor for preterm delivery. One study quotes a two-fold increase in the risk of preterm birth in mothers who had bleeding in the first trimester of pregnancy compared to mothers with no vaginal bleeding (Williams, et al., 1991). Even women with only light vaginal bleeding were also at a significantly increased risk of preterm birth (Berkowitz, et al., 1983).

Antepartum haemorrhage in the second or third trimester of pregnancy is an important risk factor for preterm birth. A bloody show is benign and does not contribute to preterm birth. Other causes of antepartum haemorrhage, including placental abruption and placenta praevia, although they represent a minority of cases of antepartum haemorrhage (Chan \& To, 1999), are more ominous and if left untreated could potentially lead to the death of the fetus and mother. Other non-obstetric causes of antepartum haemorrhage, such as bleeding from the lower genital tract or rectal bleeding need to be carefully excluded. Antepartum haemorrhage of unknown origin remains the most common cause of bleeding in pregnancy, accounting for more than $50 \%$ of all cause of antepartum haemorrhage (Chan \& To, 1999). A retrospective analysis into the timing of preterm birth and antepartum haemorrhage showed that the risk of preterm delivery, although higher with associated uterine contractions, was still significant even without contractions: $62.5 \%$ versus $13.6 \%$ (Leung, et al., 2001). 


\subsubsection{Abruption}

Evidence exists that correlates decidual bleeding with chronic uteroplacental vascular pathologic processes (Salafia, et al., 1995). Implantation of the human blastocyst involves trophoblastic invasion deep into the decidual cells of the uterus. Shallow invasion leads to inadequate decidual vascular formation and subsequent poor uteroplacental blood flow (Lockwood, et al., 2009). Placental ischaemia occurs and is implicated in the pathogenesis of placental abruption and of preterm birth (Vintzileos, 2008, Ananth, et al., 2007). Decidual bleeding at the time of formation of the placenta is associated with preterm birth through an increased risk of PPROM (Harger, 1990).

\subsection{Excessive uterine distention}

Polyhydramnios, multiple gestations, and other reasons of excessive uterine distention are well studied risk factors for PTB. Over stretching of the uterine muscle induces the formation of gap junctions, upregulation of oxytocin receptors, and production of prostaglandin E2 and F2 and myosin light chain kinase, which are critical events preceding uterine contractions and cervical dilation (Ou, CW., \& Orsino A. 1997).

\subsubsection{Abnormal amniotic fluid volumes}

Abnormal amniotic fluid volumes is associated with poor perinatal outcome. The incidence of polyhydramnios, an excess amount of amniotic fluid, ranges from $1-2 \%$ of all pregnancies depending on the diagnostic criteria used (Hill, et al., 1987, Bundgaard, et al., 2007). It is caused by fetal malformation, such as gastrointestinal obstruction, in the majority of cases, followed closely by maternal diabetes mellitus. Other causes such as fetal anaemia and congenital infection play a less significant role (Beloosesky \& Ross, 2010). Polyhydramnios causes uterine overdistension and thus predisposes pregnancies to preterm delivery. Complications associated with oligohydramnios include skeletal deformations, contractures and pulmonary hypoplasia. Preterm delivery in fetuses with no congenital anomalies, either spontaneous preterm birth or medically indicated due to maternal or fetal complications, occurs in more than $62 \%$ of cases of oligohydramnios, compared to $8 \%$ in pregnancies with normal liquor volumes (Petrozella, et al, 2011).

\subsubsection{Multiple gestations}

Multiple gestations are high-risk pregnancies, which are often complicated by preterm birth, low birth weight, neonatal morbidity and perinatal, neonatal and infant mortality. Twins and higher order multiple pregnancies account for only 2 to $3 \%$ of all births, but make up more than $17 \%$ of late preterm births, and $23 \%$ of very preterm births (Blickstein, 2006). The average birth age of most multiple gestations occurs in the late preterm period due to the occurrence of spontaneous onset of labour and iatrogenic preterm birth. $50 \%$ of all twins and more than $90 \%$ of triplets are born premature. $36 \%$ of triplets are delivered before 32 weeks gestation (Blickstein, 2006). Of the preterm pregnancies, twins are also at increased risk of being born at an earlier gestation than singleton pregnancies (Gardner, et al., 1995). Determination of chorionicity is important as the risk of preterm birth in dichorionic twins before 32 weeks is $5.5 \%$ and in monochorionic twins, 9\% (Krampl \& Klein, 2007). Iatrogenic preterm birth in monochorionic twins significantly increases the number of preterm deliveries in this type of twinning as obstetric and maternal complications are particularly high (Lee, et al., 2006). The most concerning complication associated with monochorionicity 
is twin to twin transfusion syndrome (TTTS). The management of these pregnancies is controversial especially regarding the optimal timing of delivery. Some recommend preterm delivery of monochorionic diamniotic twins, even without TTTS or other anomalies, due to the high incidence (ranging from $3.6 \%$ to $4.6 \%$ ) of unexpected intrauterine fetal death despite intensive fetal monitoring after 32 weeks of gestation (Lee, et al., 2008, Barigye, et al., 2005).

The endocrine environment produced by multiple gestations may also be a contributing factor. Multiple gestations produce a higher amount of estrogen, progesterone, and sex steroids compared to singleton pregnancies (Robinson, 2011). Increased steroid production in multiple pregnancies may play a role in initiation of preterm labor. In particular, higher peripheral levels of relaxin, associated with multiple gestations, may cause cervical insufficiency, with subsequent PTB (Weiss, et al., 1993).

The emergence of assisted reproduction technologies has increased the rate of multiple gestations.

The pathophysiology for preterm birth in multiple gestations, particularly higher order multiple gestations, may be related to uterine over-distension and increased intrauterine volume, or related complications such as cervical incompetence. Healthcare professionals should endeavor to reduce the risk of multiple gestation and pre-term labour through appropriate monitoring of patients treated with fertility drugs and limiting the number of embryos transferred. Reduction of multiple gestations, particularly high order multi-fetal pregnancies, may improve neonatal outcome.

\subsection{Uterine trauma/anomalies}

Uterine abnormalities predispose to preterm birth, due to the inability of uterus to hold the pregnancy until term. Uterine leiomyomas are the most common abnormalities observed. Pregnancies with uterine duplication anomalies, such as bicornuate uteri are more likely to be complicated by preterm birth at less than 34 weeks gestation, $29 \%$ versus a preterm birth rate of $3 \%$ at 34 weeks, with normal uteri (Cooney, et al., 1998). Unicornuate uteri, although rare, $(1: 4020)$ carries with it the poorest overall obstetric outcome with a preterm birth rate of $20.1 \%$ (Reichman, et al., 2009).

\subsubsection{Uterine leiomyoma}

Leiomyoma, better known as uterine fibroids, are benign smooth muscle neoplasms of the uterus. They arise in women of reproductive age, and in most cases are asymptomatic. Reports of an increase in the size of uterine fibroids during pregnancy have been inconsistent throughout the literature (Aharoni, 1988, Lev-Toaff, 1987, Strobel 1994). Those that do increase in pregnancy do so in the first trimester (Ouyang, 2006). The most common recognized complication of uterine fibroids in pregnancy is pain, affecting approximately $10 \%$ of women with fibroids (Rasmussen \& Knudsen, 1994).

There appears to be a small increase in the rate of preterm birth in pregnant women with uterine fibroids. This risk is further increased if there are multiple fibroids present in the uterus or if placentation has occurred next to or overlying a submucosal fibroid (Lev-Toaff). Various theories have been proposed regarding the relationship between preterm birth and fibroids. These include a localized increase in oxytocin levels and premature contractility when a gravid fibroid uterus reaches a certain size, as fibroid uteri are assumed to be less distensible than non-fibroid uteri (Ouyang, 2011). Myomectomy should be considered on an individual basis in women with a pregnancy complication or an adverse pregnancy outcome presumed due to fibroids prior to future pregnancies. 


\subsubsection{Diethylstilbestrol}

Diethylstilbestrol is a synthetic non-steroidal estrogen, initially produced for the treatment of postmenopausal symptoms and endometriosis. Historically, it was used in pregnant women with the incorrect assumption that it would reduce the rate of miscarriage and preterm birth.

In 1971 a case series, published by the New England Journal of Medicine emerged linking Diethylstilbestrol (DES) to female offspring genital tract neoplasia via transplacental carcinogenesis 15 to 22 years later (Herbst, et al., 1971). Subsequent studies into its use confirmed a predisposition to clear cell adenocarcinoma of the vagina and cervical intraepithelial neoplasia in female offspring (Hatch, et al., 2001, Troisi, et al., 2007). Women exposed to DES in-utero were also found to be at higher risk of infertility, preterm birth and adverse pregnancy outcomes. This has been attributed to the increased risk of abnormalities of the uterus, such as t-shaped uterus and uterine fibroids seen in DES daughters (Kaufman, et al., 2000). Its use in pregnant women was subsequently discontinued.

\subsubsection{Previous cervical surgery}

Cervical incompetence is dilatation and effacement of the cervix prior to term, which contributes to the loss of an otherwise healthy pregnancy. It is relatively rare accounting for $1-2 \%$ of all pregnancies in the United States, but up to $25 \%$ of all mid trimester losses. Risk factors for cervical incompetence include previous cervical surgery, and history of second trimester pregnancy loss.

The risk of preterm birth is significantly increased in women who have had cervical surgery, most notably with cone biopsies (conization) or Large Loop Excision of the Transformation Zone (LLETZ) (Kristensen, et al., 1994). In a retrospective study carried out on 624 women, who delivered post loop electrosurgical excision procedure, Jakobsson et al, found that the risk of preterm birth was higher following larger biopsies or repeated procedures, with a two and five-fold increase respectively (Jakobsson, et al., 2009). A subsequent study on the subject found that it was the presence of cervical intra-epithelial neoplasia 3 (CIN3) as opposed to cervical surgery per se that contributes to the increased the risk of preterm birth: women with CIN3 were significantly more likely to have spontaneous preterm birth compared with those without CIN, $11 \%$ versus $6 \%$ respectively (Shanbhag, et al., 2009). It is therefore important to consider that the social risk factors that predispose to CIN rather than cervical surgery alone may increase preterm birth rates in women undergoing LLETZ procedures.

\subsubsection{History of second trimester termination of pregnancy}

Speculation exists regarding the effects of termination of pregnancy as an independent risk factor for adverse obstetric outcomes. First and indeed second trimester termination of pregnancies have historically been considered minor procedures, with little thought paid to future pregnancies or fertility. Termination of pregnancies is a very common event, occurring in 21.3 out of every 1000 women per year in the United States in 2000 (Finer \& Henshaw 2003). Suspected mechanisms that predispose to preterm birth associated with termination of pregnancies include introduction of infection, with formation of uterine adhesions, and secondly, damage to the cervix leading to cervical incompetence. A systematic review of research into birth outcomes for women with a history of termination of pregnancy found that the procedure was associated with a small but statistically 
significant risk of preterm birth, in comparison to mothers who had never had a termination (8.7\% versus $6.8 \%$ respectively). Additionally, the risk of both preterm birth and low birth weight was increased with an increasing number of pregnancy terminations (Shah \& Zao, 2009). When considering these results, it is important to note that many of the other risk factors, such as smoking and low maternal body mass index, related to adverse pregnancy outcomes in this group of women undergoing termination of pregnancy.

\subsection{Psychological stressors}

The mechanisms involved in the psychosocial associations of preterm birth are not well understood. Research on psychosocial factors and preterm birth has accumulated rapidly in recent years. Some psychosocial factors implicated in the aetiology of preterm birth include major life events, chronic stress, maternal anxiety, personal racism, and lack of support (Behrman \& Butler, 2007).

\subsubsection{Major life event}

Exposure to severe life events has been linked to very and extremely pre-term births. Khashan and colleagues carried out a study evaluating the influence of exposure to severe life events and preterm, very preterm and extremely preterm birth. Exposures were defined as death or serious illness in close relatives 6 months prior to conception or in the first or second trimester of pregnancy. In their cohort of 1.35 million singleton live births, they found that maternal exposure to severe life events contributed significantly to the risk of preterm birth; severe life events in close relatives increased the preterm birth rate by $16 \%$, while if the severe life event involved an older child, the risk of preterm and very preterm birth was increased by $23 \%$ and $59 \%$ respectively (Khashan et al, 2009).

\subsubsection{Work related stressors}

With the increasing number of mothers who continue to work late into their pregnancy, occupational stress is hypothesized to be an important contributor to adverse reproductive outcomes, both for mother and baby (Mutambudzi et al., 2011). Physical stressors such as shift work, long hours standing, and heavy lifting have been consistently associated with increased risk of preterm birth (Gold et al 1994). Theoretically, having and being able to maintain a job, is an indicator in itself of a higher socioeconomic status, which has an inverse effect on preterm birth rates. Recent studies have found no increase in the rate of preterm birth and employment, but these are mainly studies carried out in developed countries, where physical strain and hazardous working conditions are not the norm.

\subsubsection{Behavioral stressors}

Behavioral stressors such as smoking, alcohol and illicit drug use, poor eating habits, sexual and physical activity, are of great importance as modifiable risk factors, as their elimination can lead to an effective reduction in the preterm birth rate. These behaviors pose specific challenges in establishing a cause and effect relationship because of their inherent complexity (Behrman \& Butler, 2007). In addition, unfavorable health activities tend to cluster: for example women with poor diets often have other potentially detrimental behaviors, such as a lack of physical activity, and vice versa (Behrman \& Butler, 2007).

In the UK in 2004, $25 \%$ of all adults were smokers (NHS). $17 \%$ of mothers continued to smoke throughout pregnancy, whilst $49 \%$ of smoking mothers gave up before or during 
pregnancy (NHS). Studies have shown that lower or stressful socioeconomic status contributes significantly to persisting to smoke during pregnancy (Weaver, 2007). Smoking is strongly related to placental abruption, reduced birth weight and infant mortality, however, the relationship of cigarette smoking to preterm birth is somewhat modest and not completely replicable (Behrman \& Butler, 2007). Its influence on pregnancy outcomes, like preterm birth, is most notable in the third trimester and there is no increased risk detected in mothers who smoke prior to the onset, or in the early stages of pregnancy (Behrman \& Butler, 2007).

High levels of alcohol use during pregnancy have detrimental effects on fetal development and subsequent neonatal survival. Women who have more than one drink a day are at an increased risk of preterm labour. According to a study carried out by Albertsen et al., 2004, the relative risk of preterm delivery and very preterm birth, $<32$ completed weeks, among women who had seven or more drinks a week during pregnancy was 1.77 and 3.26 respectively, compared to non-drinkers. If less than 4 units a week of alcohol was consumed, then there was no increased risk of preterm birth (Albertsen et al., 2004). Due the differing effects of alcohol on the fetus depending on the amount consumed and the limitations associated with selfreporting, the relationship between alcohol and preterm birth remains unclear.

Illicit drug use, especially cocaine, has been widely implicated as an important cause of preterm birth. Cocaine use in the United States rose from 3.2\% in 1972 to $12.5 \%$ in 1985, and continues to rise (Rouse, 1991). Antenatal cocaine users experience significantly increased risk of preterm birth compared with that for non-users, with an odds ratio of 3.38 (Gouin, 2011). Marijuana smoking does not appear to significantly increase the risk of preterm labour. Its adverse effects come mainly from the inhalation of combustion material (Behrman \& Butler, 2007).

Repeatedly, evidence shows that mothers who live a favorable lifestyle are at a reduced risk of adverse pregnancy outcome, including a reduction in the risk of preterm labour (Behrman $\&$ Butler, 2007). Continued efforts are required to better understand and therefore define the aspects of a positive lifestyle that are associated with a reduced risk of preterm birth.

\subsection{Ethnicity}

Preterm birth, the primary predictor of prenatal morbidity and mortality can result from diverse biologic and sociodemographic variables (Al-Eissa, \& Ba'Aqeel, 1994). The infant mortality rate for non-Hispanic Black mothers in 2002 was 13.9 per 1000 live births. This is a huge difference from the rate for non-Hispanic White mothers: 5.8 per 1000 live births (Mathews, et al., 2004). Chronic stress is a more prominent feature in the daily lives of Black women than for White women. African American women are, throughout the published literature, at a higher risk for preterm delivery. In the year 2001, the United States preterm delivery rates among Black and White women were 17.5 and 10.8 per 100 live births, respectively (Mustillo, et al., 2004). This gap persists, even after consideration for socioeconomic status, and other known risk factors. Collins et al investigated the causal mechanisms of this association. When other risk factors, such as socioeconomic condition, levels of support, cigarette smoking, alcohol and illicit drug use were excluded, they reported that African American mothers with very low birth weight infants, less than $1500 \mathrm{~g}$, were twice as likely to report experiences of racial discrimination during pregnancy than women who had infants of normal birth weight (more than 2500g) (Collins, et al., 2000). This elevated rate may account for the difference in the pre-term birth rate between the USA and other countries. 
Subsequent studies supported this finding. In a study comparing African American women who delivered low birth weight infants, who were all preterm, and matched controls, with normal birth weight infants, it was concluded that "lifelong accumulated experiences of racial discrimination experienced by African American women constitute an independent risk factor for preterm delivery" (Collins, et al., 2004).

Mustillo and colleagues carried out a 10 year prospective study on a large cohort of African American and White women who gave birth to live infants at 20 weeks gestation or longer. Firstly, they found that race was a risk factor for preterm birth. Black women were 2.5 times more likely to have a preterm delivery than White women. Those reporting racial discrimination in 3 or more situations, were 3.1 times at increased risk of preterm birth. Second, women who had experienced lifetime discrimination were almost five times more likely to deliver a low birth weight infant, (less than 2500g) than those who had not experienced any racism (Mustillo, et al., 2004). These reports suggest that lifetime experiences of racism, as a psychosocial stressor, may significantly contribute to the racial and ethnic disparities in the rates of both preterm birth and low birth weight.

\subsection{Assisted reproduction}

Worldwide, more than $10 \%$ of couples are infertile (Nelson \& Lawlor, 2011). Until recently very little could be done to help infertile or subfertile couples. Then, in July 1978, the world's first successful in vitro fertilization (IVF) baby was born. Since then, 4 million babies have been born through in vitro fertilization (Nelson \& Lawlor 2011).

Infertile couples that conceive following IVF with or without intra-cytoplasmic sperm injection (ICSI) are at an increased risk for obstetrical and perinatal complications, most notably, preterm delivery and low birth weight (Basso \& Baird, 2003). Singleton pregnancies achieved by assisted reproduction are at higher risk for adverse perinatal outcomes than spontaneous singleton pregnancies in fertile couples. Another significant risk of assisted reproduction is multiple gestations. Although the majority of twinning that occurs with assisted reproduction are dichorionic, the incidence of monochorionic twinning following assisted reproduction is $4-5$ times that of normally conceived twins: $1.88 \%$ versus $0.4 \%$, respectively (Alikani, et al., 2003). Aspects of assisted reproductive techniques, which increases the risk of preterm birth include, assisted hatching (2.35\% versus $1.58 \%$ with no assisted hatching) and day 5 or day 6 blastocyst transfer $(1.5 \%$ versus $0.2 \%$ in embryos transferred on day 2) (Alikani, 2003, Wright, 2004). This carries with it an increase in poor perinatal outcome. Risks of multiple pregnancies include higher rates of preterm birth and low birth weight with its associated perinatal mortality (Allen et al., 2006).

Nelson and Lawlor carried out a study to evaluate the factors that influence the success of assisted reproductive treatment. Among their findings, they discovered that there was a marked increase in the risk of preterm birth, if oocyte donation for female factor infertility was required. They also found that other maternal characteristics, especially maternal age and cervical causes of infertility are strongly associated with the risk of preterm delivery in singleton live births resulting from IVF (Nelson \& Lawlor, 2011).

It remains uncertain if the increased risks of preterm birth associated with assisted reproduction are attributable to the underlying infertility, characteristics of the infertile couple, or possible adverse effects of the assisted reproductive treatments (Allen et al., 2006; Basso \& Baird, 2003). The fact that infertile women who require assisted reproduction are older and are more likely to have an underlying chronic illness may also explain a patient- 
related increase in preterm birth (Blickstein, 2006). However, treatment bias, such as iatrogenic preterm birth, cannot be excluded.

\subsection{Body Mass Index}

Maternal body mass index (BMI), calculated as the weight $(\mathrm{kg})$ divided by the height $\left(\mathrm{m}^{2}\right)$, is hypothesized to play a significant role in the aetiology of preterm birth. Evidence suggests that a low pre-pregnancy weight is associated with an increased risk of preterm birth (Zhong, 2010). Al-Eissa, \& Ba'Aqeel, 1994 carried out a case control study in Saudi, to determine the risk factors that were associated with preterm birth. Their findings included a significant correlation between a maternal BMI of less than 23 and an increased risk for preterm delivery (Al- Eissa, \& Ba'Aqeel, 1994). This evidence is further supported by various other studies, most notable The Preterm Prediction Study, where it was reported that a maternal BMI of less than 19.8 was strongly associated with an increased risk of very preterm birth less than 32 weeks gestation, with a relative risk of 2.5 (Goldenberg et al., 1998).

The incidence of obesity is escalating worldwide, and has become the focus of initiatives to preclude its occurrence and reduce the associated adverse health consequences. Pregnant women who are obese are at an increased risk for certain complications during pregnancy, labour and delivery and in the post partum period. These include an increased risk of malformations, including neural tube defects, shoulder dystocia and other birth traumas, endometritis and caesarean wound infection, in comparison to non-obese women (Magann, et al., 2010). Pre-pregnancy obesity is implicated in the aetiology of preterm birth by increasing the risk of PPROM. The risk of spontaneous preterm birth in obese mothers at less than 37 weeks gestation, without PPROM is reduced: $6.2 \%$ versus $11.2 \%$ in non-obese mothers (Zhong, 2010, Hendler, 2005). This finding is supported by more recent studies on the subject with obese women in early pregnancy being more likely to have post term babies, than their non-obese controls (Khashan, \& Kenny, 2009, Magann, et al., 2010). However, indicated preterm delivery for congenital defects, large for gestational age, gestational diabetes, preeclampsia, and stillbirth, contributes significantly to the proportion of preterm birth rates in obese women (Hendler, et al., 2005).

\subsection{Maternal age}

The importance of maternal age, which has been widely reported to influence pregnancy outcomes and therefore duration, is escalating. This is due to the increasing frequency in the last 20 years of mothers bearing children at advancing ages. Women under 16 and those above 35 have a 2 to 4 percent higher rate of preterm birth compared with those between 21 and 24 years of age.

Several studies have examined the relationship between advancing maternal age and preterm delivery, with preterm births occurring in $8 \%$ of mothers more than 35 years compared to less than $4 \%$ of births among mothers younger than 35 years (Martius, 1998, \& Astolfi, 1999). This finding has been attributed to the hormonal factors associated with advancing maternal age. However, there is insufficient evidence to determine if advancing maternal age is an independent and direct risk factor for preterm birth.

Teenage mothers also carry an increased risk of adverse pregnancy outcomes including an increased risk of delivering earlier than mothers between 20 to 39 years old. They are also more likely to have higher rates of extreme prematurity (Shrim, 2011). This high proportion 
of preterm births in young mothers may be indicative of unfavourable socio-economic situations. However, it is important to remember that gestational age may be more frequently underestimated in the poorly educated or very young mothers.

\subsection{Infections}

Infections and associated inflammation are important initiators of the preterm birth pathways. This is suggested by the repeated discovery of positive bacterial cultures from the placentas or membranes of a high proportion of patients with preterm birth (Salafia, 1991). $25 \%$ of all preterm births occur in mothers with bacterial colonization of the uterus (Romero, et al., 2007). Other studies have shown that bacteria, which cause placental infection, are capable of producing prostagandins, which disrupts uterine quiescence, causing cervical softening and preterm birth (Bejar, 1981). In addition, vaginal infection and associated inflammation, causes an inflammatory response with cytokines, which cause a further increase in prostaglandin levels (Srinivasan, et al., 2009).

Raised levels of neutrophils and a raised $\mathrm{pH}$ of more than 5, was shown to be significantly associated with preterm birth. There is an inverse relationship between neutrophilia and preterm birth, with the strength of the association increasing as the gestational age at delivery decreases (Sinham, 2003). Intrauterine infection is a particularly important risk factor for adverse neurodevelopmental outcomes after PPROM. The colonization of the placenta and membranes can arise directly from the genito-urinary tract with sexually transmitted infections or from haematogenous spread with systemic infections.

\subsubsection{Sexually transmitted infections}

In evaluating the risk of spontaneous preterm birth associated with genitourinary tract infections, Andrews, et al., carried out a case control study in The Preterm Prediction Study. They found that women with Chlamydia trachomatis infection were more likely to have a short cervix less than $25 \mathrm{~mm}$, than uninfected controls (33\% versus $17.9 \%$ respectively). They also noted that infection with C. trachomatis at 24 weeks gestation predisposed the mothers to a risk of preterm delivery 2 times and 3 times that of the uninfected controls at less than 37 weeks' and less than 35 weeks' gestation respectively (Andrews, et al., 2000). Andrews et al also published a secondary analysis in 2006 on the relationship between mid-pregnancy genitourinary tract infection with Chlamydia and its association with subsequent preterm birth, refuting their primary results regarding an increased risk in Chlamydia infected mothers and preterm birth (Andrews, et al., 2006). Subsequent research in the area has resulted in conflicting results. It therefore remains uncertain if an association exists between sexually transmitted infections and preterm birth. There is some indication that it is the relative load of bacteria, or the specific species of bacterium, rather than its presence per se, that predisposes to preterm birth.

\subsubsection{Periodontal disease}

Recent evidence suggests that infections remote from the fetal site may also be causative. Bacteria are capable of entering the uterine cavity by haematogenous spread. Periodontal disease, a chronic low-grade infection, has been repeatedly implicated in the causation of preterm birth. Oral and vaginal sites are comparable in their bacterial microbiology. Mothers with periodontitis and bacterial vaginosis also share similar social and sociodemographic risk factors, suggesting a common pathophysiology (Srinivasan, et al., 2009). 
Low levels of infections and disturbances of the bacterial flora in the mouth have been shown to be enough to initiate preterm birth via the production of pro-inflammatory cytokines in the uterus (Romero, et al., 2007).

Offenbacher and colleagues, in the OCAP (Oral Conditions and Pregnancy) study, investigated obstetric outcomes in women with periodontal disease. Their results illustrate a preterm birth incidence of $28.6 \%$ in women with moderate to severe periodontal disease compared to $11.2 \%$ among women with good oral health (Offenbacher, et al., 2006). Several other studies report an inverse relationship between severe or generalized periodontal disease and decreasing gestational age at delivery, with an odds ratio of 4.45 for preterm delivery less than 37 weeks, increasing to an odds ratio of 7.07 for delivery before 32 weeks gestation (Jeffcoat, et al., 2001).

As regards antenatal treatment of periodontal disease, Offenbacher and colleagues carried out a randomized controlled trial, the Maternal Oral Therapy to Reduce Obstetric Risk (MOTOR) study, to evaluate the effect of non-surgical treatment of periodontal disease on preterm birth rates. They found that treatment of women with periodontal disease had minimal improved benefit on gestational age at delivery of less than 37, 35 or 32 weeks, $13.1 \%$ versus $11.5 \%$ in non-treated controls (Offenbacher, et al, 2009). This is in contrast to the recent Australian meta-analysis of 10 randomized trials by George et al 2011, which found that antenatal periodontal treatment significantly lowered preterm birth and low birth weight rates (George, et al., 2011).

Given the mounting evidence and continued speculation regarding the effect of periodontal disease and treatment on preterm birth, every opportunity should be taken to advise mothers about the importance of good oral health preconceptually and prevention of periodontal disease.

\subsection{Fetal factors}

\subsubsection{Congenital abnormalities}

The presence of a major congenital abnormality greatly increases the risk of preterm delivery, 3.8-fold increased risk compared with newborns without congenital malformations (Mohangoo et al., 2010). It is also associated with the presence of other risk factors that predispose to preterm birth, with pregnancies with multiple malformations at the highest risk of preterm birth. A study carried out in Washington to evaluate the relative risk of preterm birth associated with major congenital abnormalities quoted a preterm birth prevalence of $11.5 \%$ in pregnancies complicated by all congenital abnormalities (Purisch, et al., 2008). The most lethal of these, congenital cardiovascular malformations, is associated with an increased incidence of preterm birth, present in 12.5 per 1000 cases of preterm birth, in comparison with 5.1 per 1000 cases in term infants (Tanner, et al., 2005). The highest risk of preterm birth was associated with infants with congenital abnormalities of the central nervous system, respiratory system and infants with chromosomal anomalies (Mohangoo et al., 2010).

\subsubsection{Intrauterine growth restriction}

Intrauterine growth restriction (IUGR), which is classified as a fetal weight below a certain centile for gestational age is associated with an increased incidence of preterm birth. IUGR is defined as a fetus with an estimated weight at below the $3^{\text {rd }}$, $5^{\text {th }}$, or 10 th centile for gestational age according to population matched centile charts. It is obvious that the higher 
the threshold for classifying a fetus as growth restricted, the more likely it is that the fetus is a constitutionally small for gestational age fetus. The greatest risk of adverse perinatal outcome with growth restricted fetuses are those with an estimated fetal weight below the $3^{\text {rd }}$ centile, with a 10 fold increased risk of neonatal death, than normally grown babies, $26^{\text {th }}-75^{\text {th }}$ percentile or weight (McIntire, et al., 1999).

It is hypothesized that spontaneous preterm labour and birth in growth-restricted fetuses is an adaptive response of the fetus to a hostile intrauterine environment. A European study evaluating the relationship between small for gestational age fetuses and preterm birth, reports an incidence for indicated preterm delivery of more than $40 \%$ for small for gestational age fetuses, in comparison to $10.7 \%$ of control normally grown fetuses. Not surprisingly, the relationship between growth restriction and preterm delivery is stronger the earlier the gestation (Zeitlin, et al., 2000).

\subsubsection{Fetal gender}

It has been long noticed that female fetuses have a better perinatal survival than male fetuses. A study analyzing the relationship between fetal gender and preterm births confirmed this stating that male fetuses are at an increased risk of being born preterm than female fetuses, in both singleton and twin pregnancies (Cooperstock and Campbell, 1996). This finding was consistent with other studies on the subject, with male babies at higher risk of being delivered at earlier gestations than female babies, $4.4 \%$ versus $4.0 \%$ (Astolfi, 1999, Hall and Carr-Hill, 1982). Speculation exists regarding the male fetal hormonal input into the onset of labour, or the genetic disadvantage of the male fetus, evidenced by the excessive male sex percentage in adverse pregnancy outcomes (Astolfi, 1999). However, despite numerous studies on the mechanisms of preterm labour influenced by fetal gender, an explanation for this remains uncertain.

\subsection{Others}

The decision to undergo abdominal surgery during pregnancy is a difficult one. The risk and benefits of treating the surgical condition must be weighed up against the risk of adverse pregnancy outcomes, including pregnancy loss and preterm delivery. Abdominal surgery during the first and second trimester of pregnancy is not associated with a significant preterm birth risk, but this risk becomes of significance in the third trimester of pregnancy (Visser, et al., 2001).

A short inter-pregnancy interval appears to be a risk factor for adverse perinatal outcomes, including preterm birth. The optimal inter-pregnancy interval is between 18 to 23 months, with increasing risk the shorter the interval. Infants conceived at less than 6 months intervals, had an odds ratio of 1.4 for preterm birth (Zhu, et al., 1999).

\section{Future research on risk factors}

Research into the risk factors attributable to preterm birth is ongoing, with international collaboration. The SCOPE (Screening for Pregnancy Endpoints) study is an international prospective study of pregnancy outcomes. Its 3 main objectives are to distinguish women in early pregnancy at risk of developing pregnancy related complications, identify novel markers that predict each complication, and develop tests that can aid in rating individual risk. Early identification of at risk women, prediction of disease and prompt intervention provides the opportunity to dramatically improve maternal and infant health. 
The SCOPE study is further supported by the PREHOT and PREBIC studies to contribute to an increased understanding of preterm birth. Currently there are no dependable or replicable methods available to detect women at high risk of preterm birth. The Preterm birth and healthy outcome team (PREHOT), using the information from genes works under 3 themes: 1. Better prediction of preterm birth, 2. Development and testing of interventions to reduce the rate of preterm birth and 3. Examination of outcomes associated with follow up interventions. The Preterm Birth International Collaborative (PREBIC) initiative aims to improve pregnancy and birth outcomes and optimize infant health to assure optimal adult health. It too, is an international initiative investigating the causes and prevention of preterm birth and low birth weight. As with the previous 2 studies, PREBIC also focuses on use of biomarkers to identify those patients at increased risk of preterm birth and formulate intervention strategies to prevent and manage those pregnancies at increased risk for indicated preterm delivery.

\section{Conclusion}

Preterm birth and low birth weight remain the most important predictors of perinatal morbidity and mortality among otherwise healthy infants. Despite the increasing survival of preterm infants due to the improvement in skills and technologies used in their management, the incidence of preterm birth continues to increase globally. Many risk factors have been proven to be causative, while others remain under speculation needing ongoing research. Previous history of preterm birth remains by far the most accurate predictor of risk for subsequent preterm delivery. Many of the risk factors that predispose to this condition, if not correctly identified and adequately treated persist, and contribute to the rising incidence of preterm birth. It is important to note that many preterm births occur in women with no prior identifiable risk factors, and a precise mechanism cannot be determined.

Successful reduction of the perinatal morbidity and mortality associated with prematurity requires the implementation of effective risk identification and behavioural modification programs such as the SCOPE study. Every opportunity has to be grasped by health care providers to assess modifiable risk factors, and encourage mothers to avoid adverse health behaviours, such as smoking and illicit drug use. The importance of pre pregnancy optimal weight attainment, and good oral hygiene is to be reinforced and the opportunity for STI screening sought.

Finally, identification and timely referral for specialized obstetrical evaluation and management of these high risk women pre-conceptually or in early pregnancy, is important in reducing the morbidity, mortality, psychological trauma and expense associated with preterm birth. Data mining in ongoing prospective trials such as SCOPE, PREHOT and PREBIC may reveal novel clinical risk factors and lead to the development of clinical risk algorithms.

\section{References}

Aharoni, A., Reiter, A., Golan, D., Paltiely, Y., \& Sharf, M. (1988). Patterns of growth of uterine leiomyomas during pregnancy. British Journal of Obstetrics and Gynaecology. Vol. 95, No. 5, (May 1988), pp. 510-3. 
Albertsen, K., Andersen, AMN., Olsen, J., Grønbæ, M. (2004). Alcohol consumption during pregnancy and the risk of preterm delivery. American Journal of Epidemiology. Vol. 159, No. 2, (July 2003), pp. 155-161.

Al-Eissa, YA., \& Ba'Aqeel, HS. (1994). Risk factors for spontaneous preterm birth in a Saudi population. European Journal of Obstetrics \& Gynecology and Reproductive Biology. Vol. 57, No. 1, (Oct 1994), pp. 19-24

Alexander, JM., \& Cox, SM. (1996). Clinical course of premature rupture of the membranes. Seminars in Perinatology. Vol. 20, No. 5, (Oct 1996), pp. 369-74.

Alikani, M., Cekleniak, NA., Walters, E., \& Cohen, J. (2003). Monozygotic twinning following assisted conception: an analysis of 81 consecutive cases. Human Reproduction. Vol. 18, No. 9, (Sep 2003), pp 1937-43.

Allen, MC. (2008). Neurodevelopmental outcomes of preterm infants. Current Opinion in Neurology. Vol. 21, No. 2, (Apr 2008), pp 123-8.

Allen, VM., Wilson, RD., \& Cheung, A. (2006) Pregnancy outcomes after assisted reproductive technology. Journal of Obstetrics and Gynaecology of Canada. Vol. 28, No. 3, (Mar 2006), pp. 220-50.

Ananth, CV., Peltier, MR., Chavez, MR., Kirby, RS., Getahun, D., \& Vintzileos, AM. (2007). Recurrence of ischemic placental disease. Obstetrics and Gynaecology. Vol. 110, No. 1, (Jul 2007), pp. 128-33.

Andrews, WW., Goldenburg, RL., Mercer, B., Iams, J., Meis, P., Moawad, A., Das, A., Vandorsten, JP., Caritis, SN., Thurnau, G., Miodovnik, M., Roberts, J., \& McNellis, D. (2000). The Preterm Prediction Study: association of Secondtrimester genitourinary chlamydia infection with subsequent spontaneous preterm birth. American Journal of Obstetrics and Gynaecology. Vol. 183, No. 3, (Sept 2000), pp. 662-8.

Andrews, WW., Klebanoff, MA., Thom, EA., Hauth, JC., Carey, JC., Meiss, PJ., Caritis, SN., Leveno, KJ., Wapner, RJ., Varner, MW., Iams, JD., Moawad, A., Miodovnik, M., Sibai, B., Dombrowski, M., Langer, O., \& O'Sullivan, MJ. (2006). Mid-pregnancy genitourinary tract infection with Chlamydia trachomatis: association with subsequent preterm delivery in women with bacterial vaginosis and Trichomonas vaginalis. American Journal of Obstetrics and Gynaecology. Vol. 194, No. 2, (Feb 2006), pp. 493-500.

Astolfi, P., \& Zonta, LA. (1999). Risks of preterm delivery and association with maternal age, birth order and fetal gender. Human Reproduction. Vol. 14, No. 11, (Nov 1999), pp. 2891-2894.

Barigye, O., Pasquini, L., Galea, P., Chambers, H., Chappell, L., Fisk, NM. (2005). High risk of unexpected late fetal death in monochorionic twins despite intensive ultrasound surveillance: a cohort study. PLoS Medicine. Vol. 2, No. 6, (Jun 2005), pp. e172.

Barker, DJ., Osmond, C., Simmonds, SJ., \& Weild, A. (1993). The relationship of small head circumference and thinness at birth to death from cardiovascular disease in adult life. British Medical Journal. Vol. 306, No. 6875, (Feb 1993).

Basso, O., \& Baird, DD. (2003). Infertility and preterm delivery, birthweight, and Caesarean section: a study within the Danish National Birth Cohort. Human Reproduction. Vol. 18, No. 11, pp. 2478-2484

Behrman, RE., \& Butler, SA. (2007) Preterm birth: Causes, consequences, and prevention. National Academic Press, ISBN, Washington, DC.

Bejar, R., Curbelo, V., Davis, C., \& Gluck, 1. (1981). Premature labour. II. Bacterial sources of phospholipase. Obstetrics and Gynaecology. Vol. 57, No. 4, (April 1981), pp. 479-82. 
Beloosesky, R., \& Ross, MG. (2010). Polyhydarmnios. UpToDate. Vol. 19, No. 1, (Nov 2010). Available from

http://www.uptodate.com/contents/polyhydramnios?source=search_result\&sele ctedTitle=1\%7E95

Berkowitz, GS., Herlap, S., Beck, GJ., Freeman, DH., \& Baras, M. (1983). Early gestational bleeding and pregnancy outcome: a multivariable analysis. International Journal of Epidemiology. Vol. 12, No. 2, (Jun 1983), pp. 165-73.

Blickstein, I. (2006). Does assisted reproduction technology, per se, increase the risk of preterm birth? British Journal of Obstetrics and Gynaecology. Vol. 113, No. 3, (Dec 2006), pp. 68-71

Bloom, SL., Yost, NP., McIntire, DD., \& Leveno, KJ. (2001). Recurrence of preterm birth in singleton and twin pregnancies. Obstetrics and Gynaecology. Vol. 98, No. 3, (2001), pp. 379.

Bundgaard, A., Andersen, BR., Rode, L., Lebech, M., \& Tabor, A. (2007). Prevalence of polyhydramnios at a Danish hospital- a population based study. Acta Obstetricia et Gynaecologica Scandinavica. Vol. 86, No. 12, (Aug 2007), pp. 1427-31.

Chan, CC., \& To, WW. (1999). Antepartum hemorrhage of unknown origin- what is its clinical significance. Acta Obstetricia et Gynaecologica Scandinavica. Vol. 78, No. 3, (Mar 1999) pp. 186-90.

Collins, JW., David, R., Symons, R., Handler, A., Wall, S., \& Dwyer, L. (2000). Low-Income African-American Mothers' Perception of Exposure to Racial Discrimination and Infant Birth Weight. Epidemiology. Vol. 11, No. 3, (May 2000), pp. 337-339.

Collins, JW., David, RJ., Handler, A., Wall, S., \& Andes, S. (2004)Very Low Birthweight in African America Infants: The role of Maternal Exposure to Interpersonal Racial Discrimination. American Journal of Public Health. Vol. 94, No. 12, (Dec 2004), pp. 2132-2138.

Cooney, MJ., Benson, CB., Doubilet, PM. (1998). Outcome of pregnancies in women with uterine duplication anomalies. Journal of Clinical Ultrasound. Vol. 26, No. 1, (Jan 1998), pp. 3-6.

Cooperstock, M., \& Campbell, J. (1996). Excess males in preterm birth: interactions with gestational age, race, and multiple birth. Obstetrics and Gynaecology. Vol. 88, No. 2, (Aug 1996), pp. 189-93.

Damus, K., \& Petrini, JR. (2007) Cost of Hospitalisation for Preterm and Low Birth Weight Infants in the United States. Paediatrics. Vol. 120, No. 1, (July 2007), pp. 1-9.

Delobel-Ayoub, M., Arnaud, C., White-Koning, M., Casper, C., Pierrat, V., Garel, M., Burguet, A., Roze,

Finer, LB., \& Henshaw, SK. (2003). Abortion incidence and services in the United States in 2000. Perspectives on Sexual and Reproductive Health. Vol. 35, No. 1, (Jan 2003), pp. 6-15.

Gadner, MO., Goldenberg, RL., Cliver, SP., Tucker, JM., Nelson, KG., \& Copper, RL. (1995). The origin and outcome of preterm twin pregnancies. Obstetrics and Gynaecology. Vol. 85, No. 4, (April 1995), pp. 553-7.

George, A., Shamim, S., Johnson, M., Ajwani, S., Bhole, S., Blinkhorn, A., Ellis, S., \& Andrews, K. (2011). Periodontal treatment during pregnancy and birth outcomes: a meta-analysis of randomized trials. International Journal of Evidence Based Healthcare. Vol. 9, No. 2, (Jun 2011), pp. 122-47.

Gold, EB., Tomich, E. (1994) Occupational hazards to fertility and pregnancy outcome. Occupational medicine. Vol. 9, No. 3 (Jul-Sep 1994), pp. 435-69.NHS: The Health and Social Care Information Centre. Stastistics on smoking, England 2006. 
Goldenberg, RL., Culhane, JF., Iams, JD., \& Romero, R. (2008). Epidemiology and causes of preterm birth. Lancet. Vol. 371, No. 9606 (Jan 2008), pp 75-84

Goldenberg, RL., Iams, JD., Mercer, BM., Meis, PJ., Moawad, AH., Copper, RL., Das, A., Thom, E., Johnson, F.,

Gouin, K., Murphy, K., \& Shah, PS. (2011) Effects of cocaine use during pregnancy on low birthweight and preterm birth: systematic review and metanalysis. American Journal of Obstetrics and Gynaecology. Vol. 204, No. 4, (Jan 2011), pp. 340.e1-340.e12

Hall, MH, \& Carr-Hill, R. (1982). Impact of sex ratio on onset and management of labour. British Medical Journal (Clinical Research Edition). Vol. 285, No. 6339, (Aug 1982), pp. 401-3.

Harger, JH., Hsing, AW., Tuomala, RE., Gibbs, RS., Mead, PB., Eschenbach, DA., Knox, GE., \& Polk, BF. (1990). Risk factors for preterm premature rupture of fatal membranes: a multicenter case-control study. American Journal of Obstetrics and Gynaecology. Vol. 163, No. 1, (July 1990), pp. 130-7.

Hatch, EE., Herbst, AL., Hoover, RN., Noller, KL., Adam, E., Kaufmann, RH., Palmer, JR., Titus-Ernstoff, L.,

Hauth, JC. (2006). Spontaneous preterm labour and premature rupture of membranes at late preterm gestations: to deliver or not to deliver. Seminars in Perinatology. Vol. 30, No. 2, (Apr 2006), pp. 98-102.

Hendler, I., Goldenberg, RL., Mercer, BM., Iams, JD., Meis, PJ., Moawad, AH., MacPherson, CA., Caritis, SN.,

Herbst, AL., Ulfelder, H., Poskanzer, DC. (1971). Adenocarcinoma of the vagina. Association of maternal stilbestrol therapy with tumor appearance in young women. New England Journal of Medicine. Vol. 284, No. 15, (Apr 1971), pp. 878-81.

Herbst. AL., Hoover, RN. (2007). Cancer risk in women prenatally exposed to diethylstilbestrol. International Journal of Cancer. Vol. 121, No. 2, (Jul 2007), pp. 356-60.

Hill, LM., Breckle, R., Thomas, ML., \& Fries, JK. (1987). Polyhydramnios: ultrasonically detected prevalence and neonatal outcome. Obstetrics and Gynaecology. Vol 69, No. 1, (Jan 1987), pp. 21-5.

Hyer, M., Harte, P., Robboy, SJ. (2001). Incidence of squamous neoplasia of the cervix and vagina in women exposed prenatally to diethylstilbestrol (Unites States). Cancer Causes and Control. Vol. 12, No. 9, (Nov 2001), pp. 837-45.

Iams, JD, Goldenberg, RL., Mercer, BM., Moawad, A., Thom, E., Meis, PJ., McNeills, D., Caritis, SN., Miodovnik, M., Thurnau, GR., Bottoms, SE., \& Roberts, JM. (1998). The Preterm Prediction Study: recurrence risk of spontaneous preterm birth. National Institute of Child Health and Human Development Maternal-Fetal Medicine Units Networks. American Journal of Obstetrics and Gynaecologists. Vol. 178, No. 5, (May 1998), pp. 1035-40.

Jakobsson, M., Gissler, M., \& Tapper, AM. (2009). Loop electrosurgical excision procedure and the risk for preterm birth. Obstetrics and Gynaecology. Vol. 114, No. 3, (Sept 2009), pp. 504.

JC., Matis, J., Picaud, JC., Kaminski, M., \& Larroque, B. EPIPAGE Study Group. (2009). Behavioral problems and cognitive performance at 5 years of age after very preterm birth: the EPIPAGE Study. Pediatrics. Vol. 123, No. 6, (Jun 2009), pp. 1485-92.

Jeffcoat, MK., Geurs, NC., Reddy, MS., Cliver, SP., Goldenberg, RL., \& Hauth, JC. (2001). Periodontal infection and preterm birth: results of a prospective study. Journal of the American Dental Association. Vol. 132, No. 7, (Jul 2001), pp. 875-80. 
Kaufman, RH., Adam, E., Hatch, EE., Noller, K., Herbst, AL., Palmer, JR., \& Hoover, RN. (2000). Continued follow-up of pregnancy outcomes in diethylstilbestrol-exposed offspring. Obstetrics and Gynaecology. Vol. 96, No. 4, (Oct 2000), pp. 483-9.

Khashan, AS, \& Kenny, LC. (2009). The effects of maternal body mass index on pregnancy outcome. The European Journal Of Epidemiology. Vol. 24, No. 11, (Aug 2009), pp. 697705.

Khashan, AS., McNamee, R., Abel, KM., Kenny, LC., Pedersen, MG., Webb, RT., \& Baker, PN. (2008). Rates of preterm birth following antenatal maternal exposure to severe life events: a population-based cohort study. Journal of Human Reproduction. Vol. 24, No. 2, (Feb 2009), pp 429-437.

Krampl, E., \& Klein, K. (2007). Prematurity in multiple pregnancies. GynakologischGeburtshilfliche Rundschau. Vol. 47, No. 2, (2007), pp. 64-9.

Kristensen, J., Langhoff-Roos, J., Kristensen, FB., Witrup, M., \& Bock, JE. (1994). Increased risk of preterm delivery in women with earlier conization. Ugeskr Laeger. Vol. 156, No. 24, (Jun 1994), pp. 3632-5.

Lee, YM., Cleary-Goldman, J., D'Alton, ME. (2006). The impact of multiple gestations on late preterm (near-term) births. Clinics in Perinatology. Vol. 33, No. 4, (Dec 2006), pp. 777-92.

Lee, YM., Wylie, BJ., Simpson, LL., \& D'Alton, ME. (2008). Twin chorionicity and the risk of stillbirth. Obstetrics and Gynaecology. Vol 111, No. 2 Pt 1, (Feb 2008), pp. 301-8

Leung, TY., Chan, LW., Tam, WH., Leung, TN., \& Lau, TK. (2001). Risk and prediction of preterm delivery in pregnancies complicated by antepartum hemorrhage of unknown origin before 34 weeks. Gynaecologic and Obstetric Investigation. Vol. 52, No. 4, pp. 227-31.

Lev-Toaff, AS., Coleman, BG., Arger, PH., Mintz, MC., Arenson, RL., \& Toaff, ME. (1987). Leiomyomas in pregnancy: sonographic study. Radiology. Vol 164, No. 2, (Aug 1987), pp. 375-80.

Li, DK. (1999). Changing paternity and the risk of preterm delivery in the subsequent pregnancy. Epidemiology. Vol. 10, No. 2, (Mar 1999), pp. 148-52.

Lockwood, CJ., Paidas, M., Murk, WK., Kayisli, UA., Gopinath, A., Krikun, G., Huang, SJ., \& Schatz, F. (2009). Involvement of human decidual cell-expressed tissue factor in uterine hemostasis and abruption. Thrombosis Research. Vol. 124, No. 5, (Nov 2009), pp. 516-520.

Lockwood, CJ., Ramin, SM., \& Barss, VA. (2011). Overview of preterm labour and delivery. UpToDate. Vol. 19, No. 1, (Jan 2011).

MacDorman, MF., \& Mathews, TJ. (2010). Behind International rankings of infant mortality: How the United States compares with Europe. International Journal of Health Services. Vol. 40, No. 4, (2010), pp 557-88

Magann, EF., Doherty, DA., Chauhan, SP., Klimpel, JM., Morrison, JC. (2010). Pregnancy, obesity and gestational weight gain, and parity as predictors of peripartum complications. Archives of Gynaecology and Obstetrics. Nov 2010.

Martiusa, JA., Stecka, T., Oehlerb, MK., \& Wulfa, KH. (1998) Risk factors associated with preterm $(<37+0$ weeks $)$ and early preterm birth $(<32+0$ weeks): univariate and multivariate analysis of 106345 singleton births from the 1994 statewide perinatal survey of Bavaria. European Journal of Obstetrics and Gynaecology and Reproductive Biology. Vol. 80, No. 2. (Oct 1998), pp. 183-189. 
Mathews, TJ., Menacker, F., \& MacDorman, MF. (2004). Infant mortality statistics from the 2002 period: linked birth/ infant death data set. National Vital Statistics Rep. Vol. 53, No. 10, (Nov 2004), pp. 1-29.

Mathews, TJ., Menacker, F., \& MacDorman, MF. (2004). Infant mortality statistics from the 2002 period: linked birth/ infant death data set. National Vital Statistics Rep. Vol. 53, No. 10, (Nov 2004), pp. 1-29.

McIntire, DD., Bloom, SL., Casey, BM., Leveno, KJ. (1999). Birth weight in relation to morbidity and mortality among newborn infants. New England Journal of Medicine. Vol 340, No. 16, (Apr 1999), pp. 1234-8.

McNellis, D., Miodovnik, M., Van Dorsten, JP., Caritis, SN., Thurnau, GR., \& Bottoms, SF. (1998). The preterm prediction study: the value of new vs standard risk factors in predicting early and all spontaneous preterm births. NICHD MFMU Network. American Journal of Public Health. Vol. 88, No. 2, (Feb 1998), pp. 223-238

Miodovnik, M., Menard, KM., Thurnau, GR., \& Sorokin, Y. (2005). The Preterm Prediction Study: association between maternal body mass index and indicated preterm birth. American Journal of Obstetrics and Gynaecology. Vol. 192, No. 3, (March 2005), pp. 882-6.

Mohangoo, A., Lanting, C., Bennebroek, J., Verloove-Vanhorick, P., \& Buitendijk, S. (2010). Contribution of Congenital Anomalies to Preterm Birth risk in the Netherlands:457. Pediatric Research. (Nov 2010), pp. 234-5.

Moutquin, JM. (2003). Classification and heterogeneity of preterm birth. British Journal of Obstetrics and Gynaecology. Vol. 110, No. 20, (Apr 2003), pp. 30-3.

Mustillo, S., Krieger, N., Gunderson, EP., Sidney, S., McCreath, H., \& Kiefe, CI. (2004) SelfReported Experiences of Racial Discrimination and Black-White Differences in Preterm and Low-birthweight Deliveries: The CARDIA Study. American Journal of Public Health. Vol. 94, No. 12, (Dec 2004), pp. 2125-2131.

Mutambudzi, M., Meyer, JD., Warren, N., \& Reisine, S. (2011). Effects of psychosocial characteristics of work on pregnancy outcomes: a critical review. Women Health. Vol. 51, No. 1, (May 2011), pp. 279-97.

Nelson, SM., \& Lawlor, DA. (2011). Predicting Live Birth, Preterm Delivery, and Low Birth Weight in Infants Born from In Vitro Fertilisation: A Prospective Study of 144,018 Treatment Cycles. Public Library of Science Medicine. Vol. 8, No. 1, (Jan 2011), e1000386.

Offenbacher, S., Beck, JD., Jared, HL., Mauriello, SM., Mendoza, LC., Couper, DJ., Stewart, DD., Murtha, AP., Cochran, DL., Dudley, DJ., Reddy, MS., Geurs, NC., \& Hauth, JC. The Maternal Oral Therapy to Reduce Obstetric Risk (MOTOR) Investigators. (2009). Effects of Periodontal Therapy on Rate of Preterm Delivery: A randomized controlled trial. Obstetrics and Gynaecology. Vol. 114, No. 3, (Sep 2009), pp. 551-9.

Ou, CW., Orsino, A., \& Lye. SJ. (1997). Expression of connexin-43 and connexin-26 in the rat myometrium during pregnancy and labor is differentially regulated by mechanical and hormonal signals. Endocrinology. Vol. 138, No. 12, (1997), pp. 5398.

Ouyang, DW., \& Norwitz, ER. (2011). Pregnancy in women with uterine leiomyomas. UpToDate. Vol. 19, No. 1, (Jan 2011). Available from

http://www.uptodate.com/contents/pregnancy-in-women-with-uterineleiomyomas-fibroids?source $=$ search_result\&selectedTitle $=6 \% 7 \mathrm{E} 150$

Ouyang, DW., Economy, KE., \& Norwitz, ER. (2006). Obstetric complications of fibroids. Obstetric and Gynaecology Clinics of North America. Vol. 33, No. 1, (Mar 2006), pp. 153-69. 
Petrozella, LN., Dashe, JS., McIntire, DD., \& Leveno, KJ. (2011). Clinical significance of borderline amniotic fluid index and oligohydramnios in preterm pregnancy. Obstetrics and Gynaecology. Vol. 117, No. 2 Pt1, (Feb 2011), pp. 338-42.

Plunkett, J., Borecki, I., Morgan, T., Stamilio, D., \& Muglia, LJ. Population based estimate of sibling risk for preterm birth, preterm premature rupture of membranes, placental abruption and pre-eclampsia. (2008). BMC Genetics. Vol. 9, No. 44. (Jul 2008), pp. 944.

Purisch, SE., DeFranco, EA., Muglia, LJ., Odibo, AO., \& Stamilo, DM. (2008). Preterm birth in pregnancies complicated by major congenital malformations: a population-based study. American Journal of Obstetrics and Gynaecology. Vol. 199, No. 3, (Sep 2008), pp. 287.

Rasmussen, KL., \& Knudsen, HJ. (1994). Effect of uterine fibromas on pregnancy. Ugeskr Laeger. Vol. 156, No. 51, (Dec 1994), pp. 7668-70.

Reichman, D., Laufer, MR., Robinson, BK. (2009). Pregnancy outcomes in unicornuate uteri: a review. Fertility and Sterility. Vol. 91, No. 5, (May 2009), pp. 1886-94.

Robinson, JN., \& Norwitz, ER. (2011). Risk factors for preterm birth. UpToDate. Vol. 19, No. 1, (Jan 2011).

Romero, R., Gotsch, F., Pineles, B., \& Kusanovic, JP. (2007). Inflammation in pregnancy: its role in reproductive physiology, obstetrical complications, and fetal injury. Nutrition Reviews. Vol. 65, No. 12 pt 2, (Dec 2007), pp. 194-202.

Rouse, BA. (1991). Trends in Cocaine Use in the General Population, In: The Epidemiology of Cocaine Use and Abuse,

Royal College of Obstetricians and Gynaecologists. Green-top guideline. No. 44. Preterm prelabour rupture of membranes. (Nov 2006).

Russell, RB., Green, NS., Steiner, CA., Meikle, S., Howse, JL., Poschman, K., Dias, T., Potetz, L., Davidoff, MJ.,

Salafia, CM., López-Zeno, JA., Sherer, DM., Whittington, SS., Minior, VK., \& Vintzileos, AM. (1995). Histologic evidence of old intrauterine bleeding is more frequent in prematurity. American Journal of Obstetrics and Gynaecology. Vol. 173, No. 4, (Oct 1995), pp. 1065-70.

Salafia, CM., Vogel, CA., Vintzileos, AM., Bantham, KF., Pezzullo, J., \& Silerman, L. (1991). Placental pathologic findings in preterm birth. American Journal of Obstetrics and Gynaecology. Vol. 165, No. 4, (Oct 1991), pp. 934-8

Schober, S., Schade, C., pp. 5-18, DHHS publications, Available from http:/ / docs.google.com/viewer?a=v\&q=cache:whBTq7xRtHUJ:archives.drugabus e.gov/pdf/monographs/110.pdf+epidemiology+of+cocaine+use

Shah, PS., \& Zao, J. (2009). Induced termination of pregnancy and low birthweight and preterm birth: a systematic review and meta-analysis. British Journal of Obstetrics and Gynaecology. Vol. 116, No. 11, (Oct 2009), pp. 1425-42.

Shanbhag, S., Clark, H., Timmaraju, V., Bhattacharya, S., \& Criuckshank, M. (2009). Pregnancy outcome after treatment for cervical intraepithelial neoplasia. Obstetrics and Gynaecology. Vol. 114, No. 4, (Oct 2009), pp. 727-35.

Shrim, A., Ates, S., Mallozzi, A., Brown, R., Ponette, V., Levin, I., Shehata, F., \& Almog, B. (2011). Is young maternal age really a risk factor for adverse pregnancy outcome in a Canadian tertiary referral hospital. Journal of Peadiatric Adolescence and Gynaecology. (May 2011) 
Sinham, HN., Caritis, SN., Krohn, MA., \& Hillier, SL. Elevated vaginal pH and neutrophils are associated strongly with early spontaneous preterm birth. American Journal of Obstetrics and Gynaecology. Vol. 189, No. 4, (Oct 2003), pp1150-4.

Srinivasan, U., Misra, D., Marazita, ML., \& Foxman, B. (2009). Vaginal and oral microbes, host genotype and preterm birth. Medical Hypotheis. Vol. 73, (June 2009), pp. 963-75.

Strobelt, N., Ghidini, A., Cavallone, M., Pensabene, I., Ceruti, P., \& Vergani, P. (1994). Natural history of uterine leiomyomas in pregnancy. Journal of Ultrasound in Medicine. Vol. 13, No. 5, (May 1994), pp. 399-401.

Tanner, K., Sabrine, N., \& Wren, C. (2005). Cardiovascular malformations among preterm infants. Paediatrics. Vol. 116, No. 6, (Dec 2005), pp. 833-8.

Troisi, R., Hatch, EE., Titus-Ernstoff, L., Hyer, M., Palmer, JR., Robboy SJ., Stronhsnitter, WC., Kaufman, R.,

Vintzileos, AM. (2008). Ischemic placental disease is the main cause for indicated preterm births. The Female Patient. Vol. 33, No. 12, (2008), pp. 53-67.

Visser, BC., Glasgow, RE, Mulvihill, KK., \& Mulvihill, SJ. (2001). Safety and timing of nonobstetric surgery in pregnancy. Digestive Surgery. Vol. 18, No. 5, (2001), 409-17.

Weaver K., Campbell, R., Mermelstein, R., \& Wakschlag, L. (2007). Pregnancy Smoking in context: The influence of Multiple levels of stress. Oxford Journals. Vol. 10, No 6, (Sept 2007), pp. 10665-1073.

Weiss, G., Goldsmith, LT., Hagen, S., \& Lederer, K. (1993). Elevated first-trimester serum relaxin concentrations in pregnant women following ovarian stimulation predict prematurity risk and preterm delivery. Obstetric and Gynaecology. Vol. 82, No. 5, (Nov 1993), pp. 821-8.

Wilcox,AJ., Skjaerven, R., \& Lie, RT. (2008). Familial patterns of preterm delivery: maternal and fetal contributions. American Journal of Epidemiology. Vol. 167, No. 4, (Feb 2008), pp. 474-9.

Williams, MA., Mittendorf, R., Lieberman, E., \& Monson, RR. (1991). Adverse infant outcomes associated with first trimester vaginal bleeding. Obstetrics and Gynaecology. Vol. 78, No. 1, (Jul 1991), pp. 14-8.

Wright, V., Schieve, LA., Vahratian, A., \& Reynolds, MA. (2004). Monozygotic twinning associated with day 5 embryo transfer in pregnancies conceived after IVF. Human Reproduction. Vol. 19, No. 8, (May 2004), pp. 1831-36.

Zeitlin, J., Ancel, PY., Saurel-Cubizolles, MJ., \& Papiernik, E. (2000). The relationship between intrauterine growth restriction and preterm delivery: an empirical approach using data from a European case-control study. British Journal of Obstetrics and Gynaecology. Vol. 107, No. 6, (Jun 2000), pp. 750-8.

Zhong, Y., Cahill, AG., Macones, GA., Zhu, F., \& Odibo, AO. (2010). The association of prepregnancy maternal body mass index and preterm delivery. American Journal of Perinatology. Vol. 27, No. 4, (April 2010), pp. 293-8.

Zhu, BP., Rolfs, RT., Nangle, BE., \& Horan, JM. (1999). Effect of the interval between pregnancies on perinatal outcomes. New England Journal of Medicine. Vol.340, No. 8, (Feb 1999), pp. 589-94. 


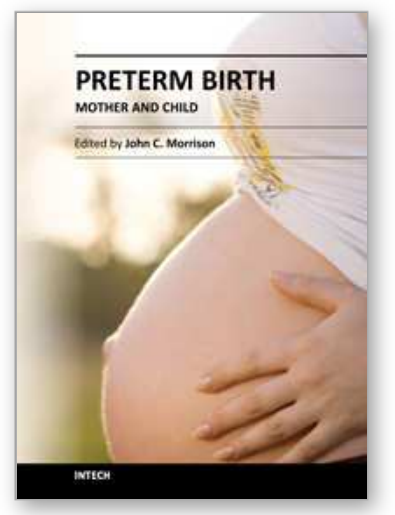

\author{
Preterm Birth - Mother and Child \\ Edited by Dr. John Morrison
}

ISBN 978-953-307-828-1

Hard cover, 368 pages

Publisher InTech

Published online 27, January, 2012

Published in print edition January, 2012

While there are many studies and books regarding preterm birth, both the obstetric and in the neonatal/pediatric literature, what is missing is the integration of data from obstetrics through neonatal course and into pediatrics as the neonate transverses childhood. A continued dialogue between specialties is essential in the battle against preterm birth in an attempt to relieve the effects or after-effects of preterm birth. For all of our medical advances to date, preterm birth is still all too common, and its ramifications are significant for hospitals, families and society in general.

\title{
How to reference
}

In order to correctly reference this scholarly work, feel free to copy and paste the following:

Ifeoma Offiah, Keelin O'Donoghue and Louise Kenny (2012). Clinical Risk Factors for Preterm Birth, Preterm Birth - Mother and Child, Dr. John Morrison (Ed.), ISBN: 978-953-307-828-1, InTech, Available from: http://www.intechopen.com/books/preterm-birth-mother-and-child/clinical-risk-factors-for-preterm-birth

\section{INTECH}

open science | open minds

\section{InTech Europe}

University Campus STeP Ri

Slavka Krautzeka 83/A

51000 Rijeka, Croatia

Phone: +385 (51) 770447

Fax: +385 (51) 686166

www.intechopen.com

\section{InTech China}

Unit 405, Office Block, Hotel Equatorial Shanghai

No.65, Yan An Road (West), Shanghai, 200040, China

中国上海市延安西路65号上海国际贵都大饭店办公楼 405 单元

Phone: +86-21-62489820

Fax: $+86-21-62489821$ 
(C) 2012 The Author(s). Licensee IntechOpen. This is an open access article distributed under the terms of the Creative Commons Attribution 3.0 License, which permits unrestricted use, distribution, and reproduction in any medium, provided the original work is properly cited. 